\title{
Study of Developmental Defects in Fetus
}

\author{
I.Rajashree ${ }^{1}$, T. Sobha devi ${ }^{2}$ \\ ${ }^{1}$ Associate professor, Department of anatomy, osmania medical college, Hyderabad, NTRUHS, A.P, India \\ ${ }^{2}$ Assistant professor, Department of Anatomy, S.V.Medical college, Tirupathi,NTRUHS, India
}

\begin{abstract}
Knowledge of embryology, teratology, clinical genetics and diagnostic ultrasonography have paved way to identity the anomalies and treat them successfully in pre/postnatal phase.Tremendous advancement in the imaging technique and availability of sophisticated instruments have made prenatal fetal surgery to repair many of the anomalies possible - an unimaginable dream come true. In this era where family planning has been accepted by all. It is imperative to take measures to identify anomalies during prenatal phase, so that in cases of major anomalies, MTP can be advised to avoid economic burden and domestic difficulties to the parents. The present study was done on 50 still born and aborted fetus around age group of 26 weeks to 40 weeks obtained from Gandhi Hospital Secunderabad. Observations found are Gastrointestinal tract anomalies are 5, Central nervous system anomalies were 6, Urogenital system anomalies are 1 in number, normal foetus are 40 cases. The primary importance to examine the malformed foetus is to derive more information which can be used to counsel parents in respect of future pregnancies.
\end{abstract}

Keywords: Anencephaly, Spinabifida, Imperforate anus, Gastroschisis, Congenital anomalies, Foetus.

\section{Introduction}

Congenital defects and anomalies present at birth have induced curiosity in people, since the dawn of history. In early societies, the babies surviving with developmental defects were considered as Monsters and were thought to be a curse on the mother or family. Prehistoric period reveals the records of human congenital malformations in cave paintings, sculptures and in writings. Archeologists have found skeletons of malformed infants dating as far back as the Stone Age. In the dark middle ages, mothers were burnt for the alleged curse of giving birth to a malformed child.

In $7^{\text {th }}$ and $8^{\text {th }}$ centuries Harvey Wolf, von Haller, Hunters and others initiated the theory of embryonic arrest to explain malformations by their knowledge of embryology.Knowledge of embryology ,teratology , clinical genetics and diagnostic ultrasonography have paved way to identity the anomalies and treat them successfully in pre/postnatal phase .Tremendous advancement in the imaging technique and availability of sophisticated instruments have made prenatal fetal surgery to repair many of the anomalies possible - an unimaginable dream come true.In this era where family planning has been accepted by all. It is imperative to take measures to identify anomalies during prenatal phase, so that in cases of major anomalies, MTP can be advised to avoid economic burden and domestic difficulties to the parents.

In 1749 Watson suggested that fatal disease acquired by transplacental route might be a cause for congenital anomalies citing variola as an example, thus proving the importance of maternal environment on the developing fetus. In 1818 saint Hilaire experimented on chick embryos and with this approach the era of experimental embryology began.

At present teratogens in the form of pathogens extensive chemicals used in day-to-day life and drugs consumed by the mother have resulted in the increased incidence of anomalies.

The primary importance to examine the malformed foetus is to derive more information which can be used to counsel parents in respect of future pregnancies .Understanding the etilogical factors in the causation of anomalies definitely plays an important role in the prevention. Early detection and excellent surgical management has resulted in the children reaching better adulthood with better life expectancy.Hence the present study is undertaken to throw more light if possible on the subject by studying autopsy finding. These babies and internal anomalies were studied in detail and photographs were taken wherever necessary.

\section{Material and Methods}

The present study was done on 50 still born and aborted fetus around age group of 26 weeks to 40 weeks obtained from Gandhi Hospital Secunderabad, which is a reputed referral center and undergraduate and postgraduate teaching hospital attached to Gandhi Medical College, Secunderabad.The fetuses were brought to the department of Anatomy Gandhi Medical College Secunderabad. They were thoroughly cleaned, numbered and prepared for study. A detailed examination of external features was performed.Sex of the fetus was recorded and the length of each specimen was measured. The head was examined for details like extent of absence of bones of skull, state of development of eyes. The morphology of the nose studied. Apart from these 
the ears tongue, mouth, lips, palate and lower jaw were thoroughly examined. The state of development of neck was recorded next.The region of the vertebral column that is the midline region on the back of the trunk was carefully observed for any discontinuity. The upper and lower limb were examined to detect any visible anomalies such as supernumary or absence of digits. The length of both the limbs were recorded. The upper limb from acromian to the tips of the middle finger and the lower limb from anterior superior iliac spine to the medial mallelous. Circumfernce of the chest and position and abnormalities of the nipples were also noted. Examination of the external features was followed by dissection of the fetus to study viscera in the thorax and abdomen.

\section{Observations}

Table .1,2 figures.1,2,3,4,5 6, 7, 8, 9 showed the observations

Table no. 1 Summary of observations

\begin{tabular}{|c|c|}
\hline Case no & Normal/abnormal \\
\hline $1,2,3,4,5,6,7$ & Normal foetus \\
\hline 8 & $\begin{array}{l}\text { Male Anencephlic foetus, brain not developed, skull bones not } \\
\text { developed, protruding eyes }\end{array}$ \\
\hline 9,10 & Normal foetus \\
\hline 11 & Male foetus with imperforate anus, low anorectal anomaly \\
\hline 12 & Male foetus with polycystic kidney, imperforate anus \\
\hline 13,14 & Normal foetus \\
\hline 15 & $\begin{array}{l}\text { A case of female with anencephaly, spina bifida, , brain not } \\
\text { developed, skull bones not developed, protruding } \\
\text { eyes, vertebral column deformed upto T12 level(spina bifida) }\end{array}$ \\
\hline $16,17,18,19$ & Normal foetus \\
\hline 20 & Female foetus with congenital diaphragmatic hernia \\
\hline 21,22 & Normal foetus \\
\hline 23 & Female foetus with gastroschisis \\
\hline $24,25,26$ & Normal foetus \\
\hline 27 & Male foetus with Hydrocephalus \\
\hline $28,29,30,31$ & No CNS anomaly \\
\hline 32 & Male foetus with Bilateral cleft lip,cleft palate, anencephaly \\
\hline $33,34,35,36,37$ & No CNS anomaly \\
\hline 38 & Male foetus with meningocoel, gastroschisis \\
\hline $39,40,41,42,43$, & No CNS anomaly \\
\hline 44 & Female foetus wirh Anencephaly, spina bifida \\
\hline $45,46,47,48,49,50$ & No CNS anomaly \\
\hline
\end{tabular}

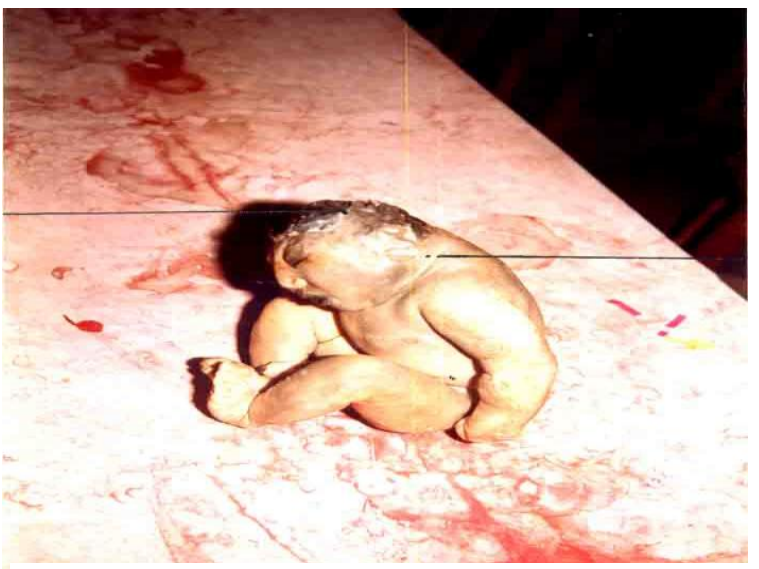

Figure 1 Male Anencephlic foetus, brain not developed, skull bones not developed, protruding eyes

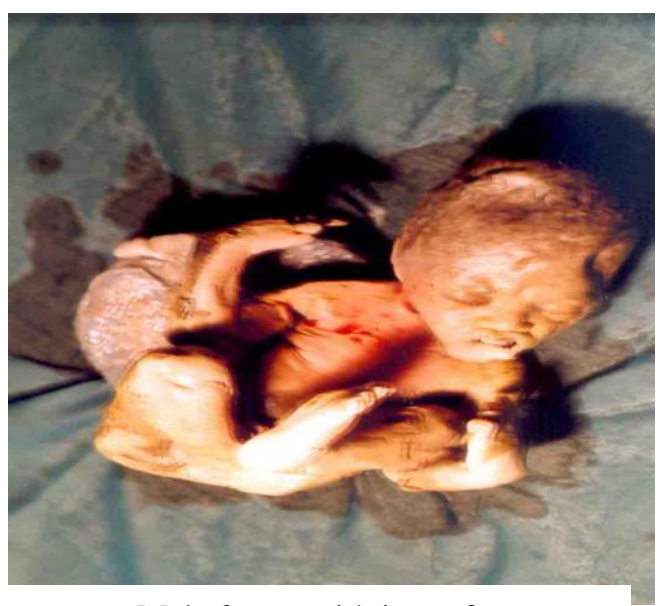

Figure 2 Male foetus with imperforate anus, low anorectal anomaly 


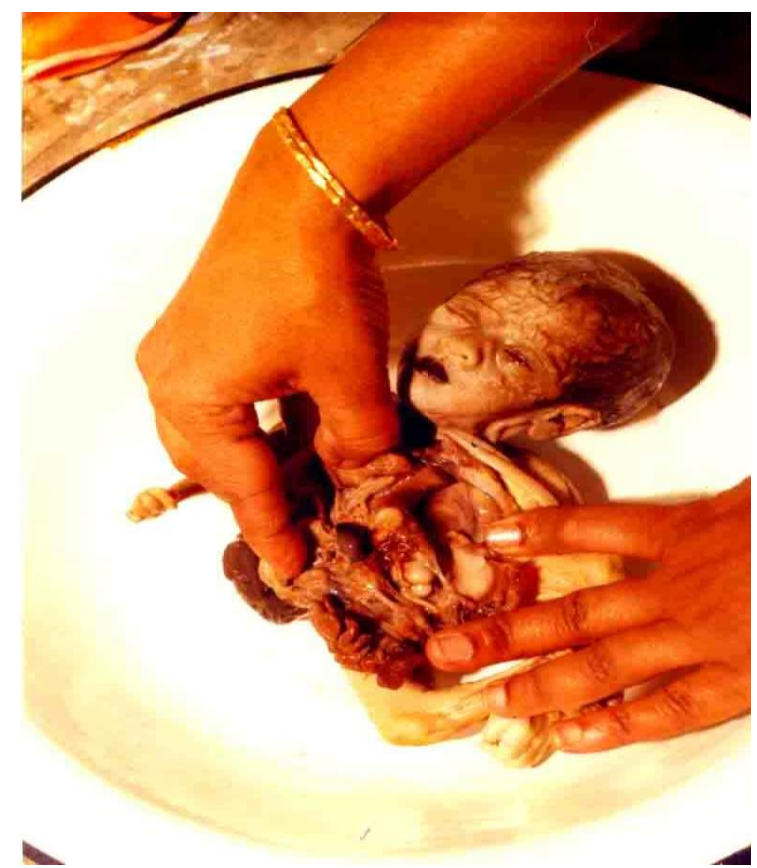

Figure 3 Male foetus with polycystic kidney, imperforate anus

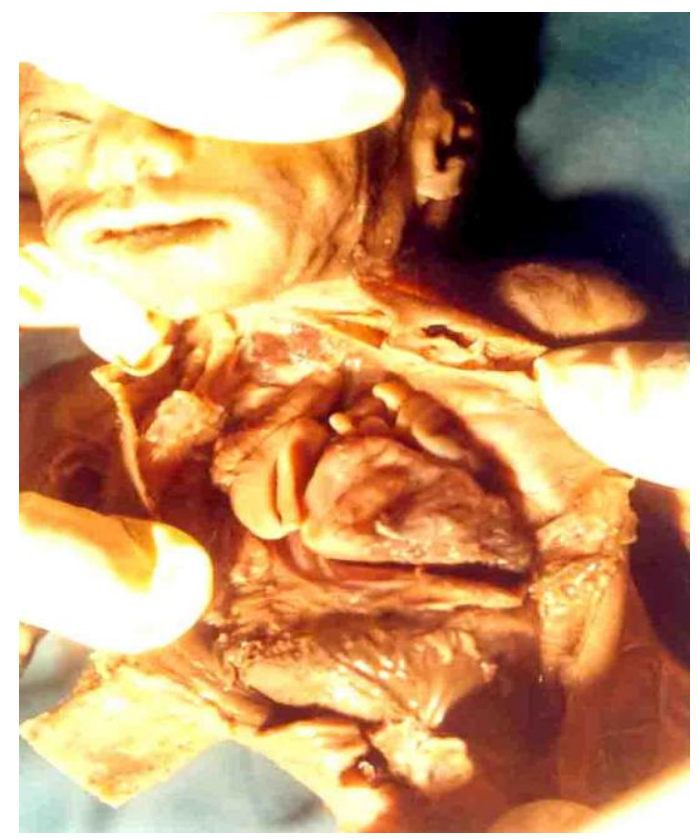

Figure 5 Female foetus with congenital diaphragmatic hernia

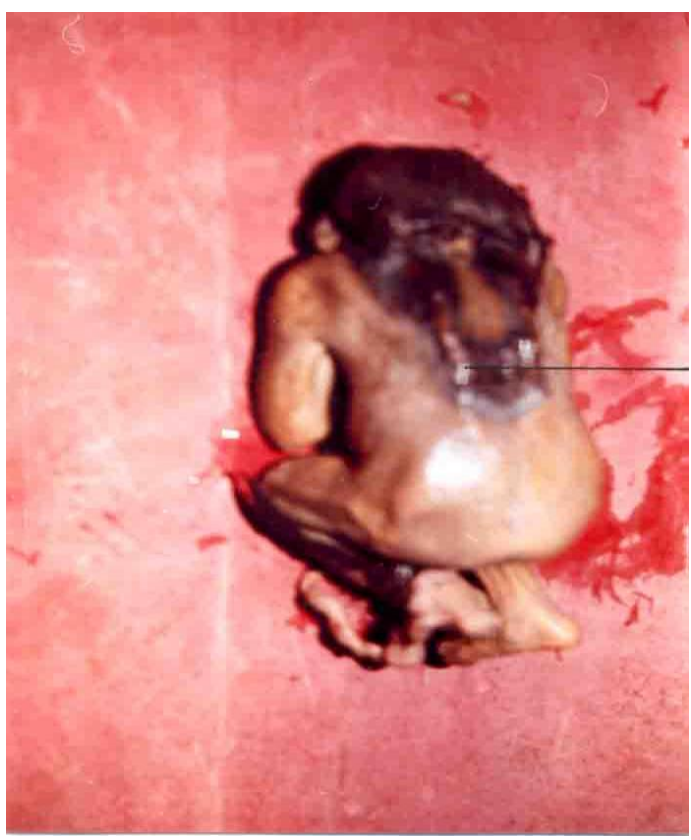

Figure 4 A case of female with anencephaly, spina bifida, , brain not developed, skull bones not developed, protruding eyes, vertebral column deformed upto T12 level(spina bifida

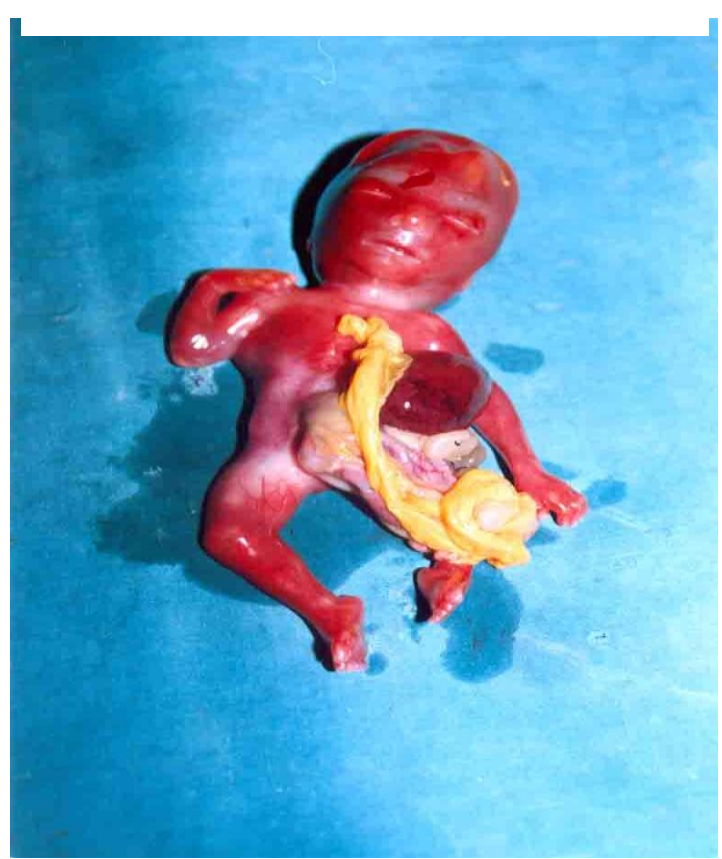

Figure 6 Female foetus with gastroschisis 


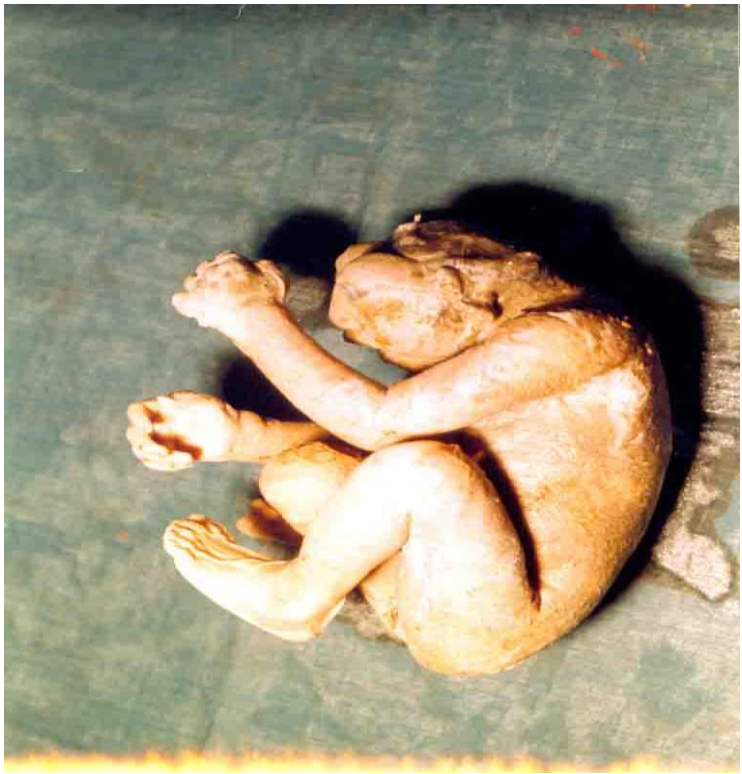

Figure 7 Male foetus with Bilateral cleft lip,cleft palate, anencephaly

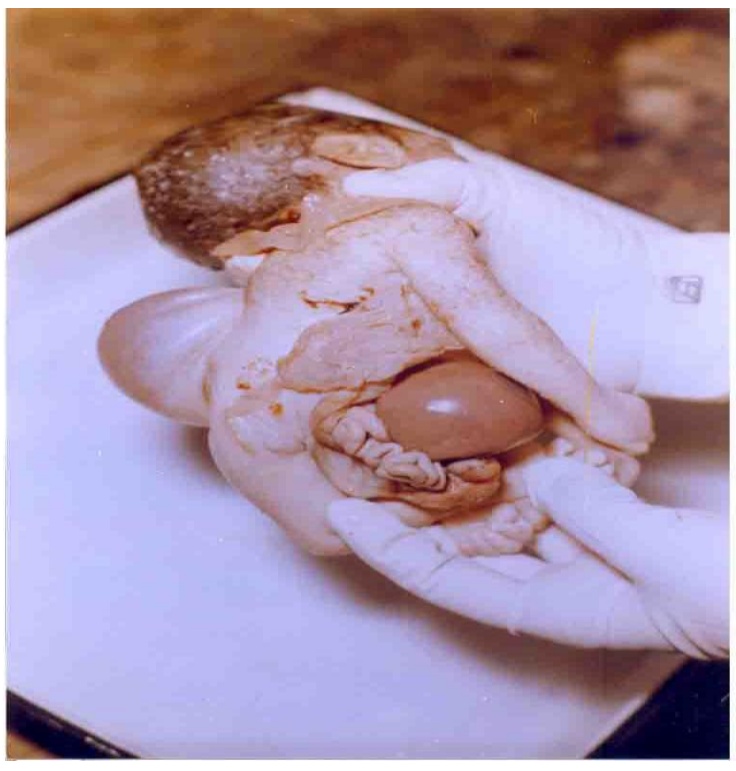

Figure 8 Male foetus with meningocoel, gastroschisis

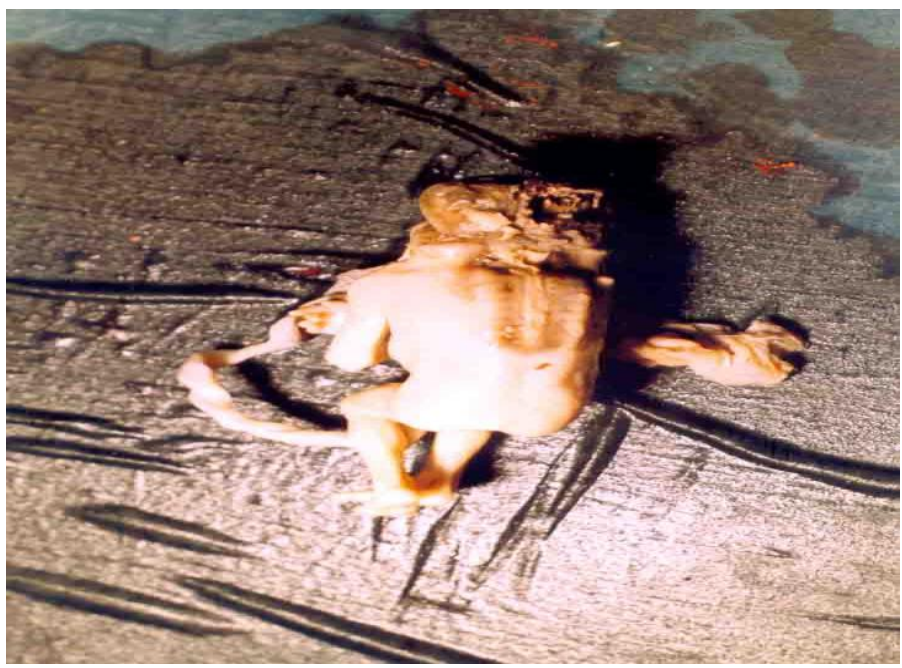

Figure 9 Female foetus wirh Anencephaly, spina bifida

Table 2 Summary of observations

\begin{tabular}{|l|c|c|}
\hline \multicolumn{1}{|c|}{ Anomalies } & Number & Percentage \\
\hline $\begin{array}{l}\text { Cardio vascular } \\
\text { system }\end{array}$ & Nil & - \\
\hline Gastro intestinal tract & 5 & $10 \%$ \\
\hline $\begin{array}{l}\text { Central nervous } \\
\text { system }\end{array}$ & 6 & $12 \%$ \\
\hline Urogenital system & 1 & $2 \%$ \\
\hline Normal cases & 40 & $80 \%$ \\
\hline
\end{tabular}

\section{Discussion}

In the through search of the past literature abnormalities of the central nervous system were reported to be 5.9 per 1000 live births as reported by Coffvi and Edwards in 1957(Ref 2). The incidence observed by the present study is at higher side i.e., $12 \%$ in which the author has dissected 50-still born and aborted fetus and found 12 of them had central nervous system abnormalities of anencephaly to spina bifida. Muffarij in 1963(Ref 10) found that 2 out of 1000 births were anencephalies ranging.2\%but the present study shows a quite high 
range of 4/50 i.e., $8 \%$ anencephalic fetuses. Aiyar in 1969(Ref 1) reported 1 case of meningocele.In the present study also 1case of meningocele was found. Vare and Bansal In 1971(Ref 16), reported cases of central Nervous system abnormalities in which they noticed 3 cases of spine bifida per 1000 cases i.e., $.3 \%$ of. They noticed that 6 of the cases of spina bifida extended through out the length of the vertebral column. Aiyar also reported a case of spina bifida where the spinal cord was exposed up to the lower lumbar region.In the present study the author noticed 1 case out 50 specimens ranging $2 \%$, which is extending up to $\mathrm{T}_{12}$ level. Vogel and Maclenahal in 1957(Ref 17) also reported 14 Anencephalic cases in which they reported that spinal cord was found to be of normal size. Present author has found 4 cases of anencephaly were spinal cord is normal in 2 cases and spina bifida in 2 cases 4 out of 40 cases i.e., $10 \%$ as found by Tensel zbeb in 2004(Ref 15), by using MR imagining had central nerves system abnormalities. In the present study by open dissection the author found a similar incidence 6 out of 50 specimens i.e., $12 \%$. The incidence reported by Comerford(Ref 3) was 6.5 per 1000 were Anencephlic( table 3, chart 1).

Lamire in 1985(Ref 7) noticed a very high incidence of cardiovascular anomalies which is $57 \%$ a very high figure and 37\% seen by Sharland G.Simpson.J in 2004(Ref 14). But the present author has not noticed any cardiovascular abnormalities.Seluck(Ref 13) in 1966 has mentioned central nervous system and cardio vascular system abnormalities are associated. He has not mentioned any frequency.

Farhataziz N.Engels(Ref 5) in 2005 reported 53\% cases of gastrointestinal tract anomalies. Which is high compared to the present study of $10 \%$. Vogel and Macclenahan(Ref 17) depicted a case of incomplete rotation of the gut and umbilical hernia in another case.The present study has reported a case of diaphragmatic hernia in which case the abdominal organs like the stomach and the intestines were pushed into the thoracic cavity and heart and lungs were displaced to one side. Anorectal anomalies were also reported by the author in which there was an imperforate anus associated with anorectal anomaly (table 4, chart 2).

The author also reported a single case in which the fetus had polycystic kidney and associated anorectal anomaly. Which was not reported in the literature studied.In 1952 Vogel and Maclennahan(Ref 17) also reported a case of hydronephrosis and hydroureter in there studies where as the author has not noticed any search case. Farhataziz in 2005(Ref 5) in MRI studies has reported also reported 37 cases of genitourinary anomalies in his studies which is quite a vast figure when compared to the low figure $2 \%$ in the present study.Lamire in(Ref 7) 1972 reported absence of kidney in a case and hyperlobulated in another case of the fetus. The present study also found a similar finding in a single case of kidney abnormality (table 5, chart 3). In the present study could not find any suprarenal anomalies which was reported earlier by Vare and Bansal in 1971 in 2 cases in a study of 39 specimens

Table 3 COMPARISION OF CENTRAL NERVOUS SYSTEM ABNORMALITIES

\begin{tabular}{|c|c|c|c|}
\hline S.No & Authors & C.N.S & Percentage \\
\hline 1 & Tamsel.S. Ozbek & $4 / 40$ & $10 \%$ \\
\hline 2 & Lammer & $18 / 21$ & $85 \%$ \\
\hline 3 & Coffvi \& Edwards & $5.9 / 1000$ & $0.59 \%$ \\
\hline 4 & Muggariji \& Kilijam & $2 / 1000$ & $0.2 \%$ \\
\hline 5 & Vogel \& Meclenahan & 14 & \\
\hline 6 & Comerford & $6.5 / 1000$ & $0.6 \%$ \\
\hline 7 & Seluck & $.5 / 1000$ & $0.5 \%$ \\
\hline 8 & Vare \& Bansal & $3 / 1000$ & $0.3 \%$ \\
\hline 9 & Present author & $6 / 50$ & $12 \%$ \\
\hline
\end{tabular}

Table 4 COMPARISION OF GASTRO INTESTINAL TRACT ANOMALIES

\begin{tabular}{|c|c|c|c|}
\hline S.No & Author & G.I.T & Percentage \\
\hline 1 & Farhat aziz .N & $37 / 80$ & $43 \%$ \\
\hline 2 & Laimre & $3 / 50$ & $6 \%$ \\
\hline 3 & Present author & $5 / 50$ & $10 \%$ \\
\hline
\end{tabular}

Table 5 COMPARISION OF UROGENITAL SYSTEM ABNORMALITIES

\begin{tabular}{|c|c|c|c|}
\hline S.No & Study & Urogenital system & Percentage \\
\hline 1 & Farhat aziz & $37 / 80$ & $43 \%$ \\
\hline 2 & Vogel \& Meclenahan & 1 & $6 \%$ \\
\hline 3 & Lamire & $3 / 50$ & $2 \%$ \\
\hline 4 & Present author & $1 / 50$ & \\
\hline
\end{tabular}



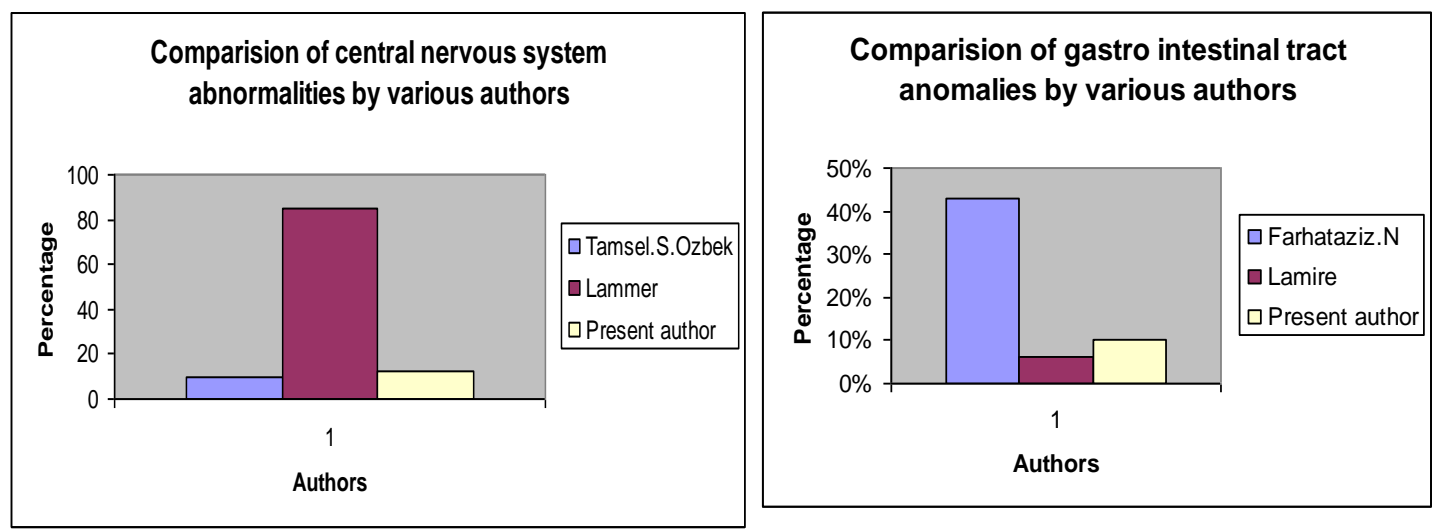

Chart 1

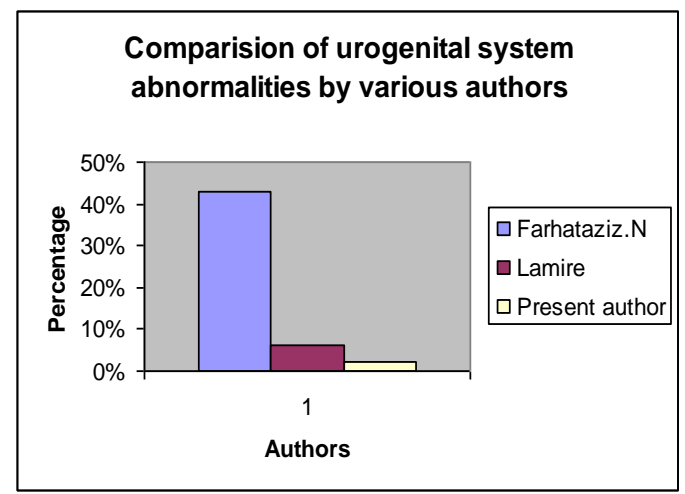

Chart 3

\section{Conclusion}

After an attempt to study the congenital anomalies of fetus the present author observed that the findings are variable with findings of the earlier studies. The author found a high incidence of central nervous system anomalies which suggest that they may be due to nutritional defiencies like folic acid and vitamin B 12 as the present study involved people from rural areas around Hyderabad and Secunderabad in a low socio economic groop. The author found gastrointestinal tract anomalies at a lower incidence in the present study compare to the earlier authors the authors feels it is due to the small cross sectional study of fetus Genito urinary tract anomalies are also of few incidence. Cardiovascular system anomalies are about $37 \%$ by various authors but such incidence was not found by the author and the author feels it is due to the fact that the previous authors have studied already established diseased subjects in hospitals covering a larger population.

\section{References}

[1]. Aiyer P.R. (1969) congenital malfarmations. Paediatric clinic of India Volume No: 4 October: $369-371$

[2]. Coffvi .V.P. and Jessop.W.J.E. a study of 137 cases of anencephaly Brit. Preventive Medicine (1957) 11:174-180.

[3]. Commenford. J.Pregnancy with congenital anomalies Lancet X.1965 Cited by Vare-Banasal.

[4]. Edward .J.H. congenital Malformations in Scotland British journal. Preventive social and Medicine 1958, 12:115.

[5]. Farhataziz.N. Engels.J.E, Ramus .R.M, Zaretsky.M, Twickler.D.M, AmJ.Roentgenol 2005 June 184 (6) PMID 15908548

[6]. Jones, Edger. OHorga ultrasound diagnosis of fetal malformations. Americal Journal of Obstretics \& Gynaecology 1973 163: 42.

[7]. Lammer 1985 in fetal congenital Anomalies - an analysis Americal Journal of Obstretics \& Gynaecology 1985 91:870.

[8]. Lamire.J, Ronald. Brue Beck with and Thomas A comparitive study of eight human specimens 1972 Tetralogy 6: 27-36.

[9]. Mac Mohan .B. Paugh.TE and Ingalls .T.H. Congenital defects incidence related to sex, race and siblings. British Journal Prev and Soc and Medi 1953, 7:211

[10]. Muffarij .I.K, and Kilejan, V.O. Anencephaly-an analysis of anencephalic births 1963, 22:257.

[11]. Persaud, Moore .The developing human, $6^{\text {th }}$ edition pg 176 W.B. Sauders Company.

[12]. Samir .C.Mithra , Human anencephalic monsters Indian jou of paediatrics 1968, 35: 480.

[13]. Seluk Eruz and Theodore .M.King anencephaly a survey of 44 cases. Obstretics \& Gynaecology 1966 27: 601

[14]. Shar land .G. Simpson .J. 2004 Prenatal diagnosis June 24 (6) 418-23 Fetal medicine unit . North wing St Thomas Hospital London.1522 9838 Pubmed.

[15]. Tamsel .S. Ozbek.SS .Senar.Rn, Oztekin .O, Demipolat .G. Department of Radiology . Bornova comparative medicine imaging Graph 2004 April 28 (3) (4)-9.

[16]. Vare AM and Bansal P.C An anatomical study of congenital anomalies. Indian journal of Paediatrics 1971, $38: 301$.

[17]. Vogel Stephen .F and Macclenahan .L, Anomalies major cerebral vessels and associated congenital malformations American journal of Pathology 1952, 28:70, -723.

[18]. Wei: P.Y.and Chen Y.P. congenital malformations in Taiwan. American journal of Obstretrics \& Gynaecology 1965 $91: 870$. 